\title{
Building Small-Medium Industry Institution Towards Sustainable Dynamic Small Industry
}

\author{
Oesman Raliby ${ }^{1}$, Effendi Bin Mohamad ${ }^{2}$ \\ Dept of Industrial Engineering-Muhammadiyah Magelang University, Indonesia ${ }^{1}$ \\ Faculty of Manufacturing-Universiti Teknikal Malaysia Malaka, Malaysia ${ }^{2}$
}

raliby@gmail.com ${ }^{1}$,bmohmmad@gmail.com ${ }^{2}$

\begin{abstract}
Putting SME's as the primary basis in development takes good commitment and coordination amongst stakeholders, government, people in business, and a non-business institution as well as the local community by applying the aggressive institution-based strategy. The research aims to construct an institutional framework model of small and medium-sized enterprises to become a dynamic, sustainable and robust business group. The approach used was FGD with some SME's businessmen by using Participative Rural Appraisal in exploring the wishes of the institutional business development. The analysis method used was partial least square-structural equation modelling (PLS-SEM) with software smart PLS 3.0. The result showed that both internal and external factors affected the performance of SME's. The result of this activity showed the frame of competitiveness model of SME's in Indonesia, which described several factors that support dynamization and competitiveness of SME's. The Goodness of Fit test showed that the Adjusted $\mathrm{R}$-squared value was 0.365 and 0.667 . Several factors gathered were a set of institutional development factors that include actor empowerment and resources connectivity factors. SME's developers rarely raise the last two elements. The previous two factors moderate external and internal factors as significant as $36.5 \%$ and $66.7 \%$. The influence of these two factors can contribute to the institutional resilience of SME's so that small industries can be more dynamic, competitive, independent and sustainable.
\end{abstract}

Keywords: SME's Institution, Dynamic Industry, Sustainable, Structural Equation Modelling.

\section{Introduction}

SME's in Indonesia, has quite essential roles, especially in the national economy. It is specifically seen in domestic income growth, the population of business and businessmen, as well as jobs provision. According to the publication of IMF and World Bank, Indonesian economic grows 5.06\% Year of a year (YoY). The condition is stable and still above the global 
trend. The domestic economy is also supported by the low inflation level and maintained around the target of government and Bank Indonesia[1].

It is admitted that SME's has a significant role in helping to solve problems of unemployment and imbalance of income distribution as well as the sectoral and regional economic structure. Many SME's survive and grow on their own although they have limited access to the resources. Meanwhile, dynamic moves of the micro business in free productive economic activities among a group of communities show an opportunity to improve their standard of living. Through the upgrading of microenterprises to Small Dynamic Enterprise namely SME's group, which can do business by cooperation (taking subcontract job) and export. Many parties have made an effort to become dynamic micro enterprises in carrying out accompaniment, guidance, and training so that SME's become independent, secure, and sustainable, by the sustainable development goals. Sustainable Development Goals (SDGs) are the master plan, which is oriented to the world's future and human survival. SDGs have a comprehensive concept to improve human welfare, world peace and nature reservation generally. Therefore, the development encouraged is not only to get high profit but also to be sustainable and environment-friendly as well as concerning social welfare. The idea of SDGs is not apart from the success of MDGs (Millennium Development Goals), which ended in 2015. SDGs, as the development of MDGs, have 17 goals of sustainable development with 196 targets. Therefore, SDGs program has a wider scope and is better prepared with universal necessity, with development principle "No One will be Left Behind" [2].

The embodiment of SDGs in the industrial sector is aligned with SDGs' goals that always feature sustainable industrial development. Therefore, it takes a development concept of industries which are independent, strong but environment-friendly, and able to give social effect and economically to prosper. Sustainable Development Goals (SDGs) was holistically for realising the global vision to the development order, which is safe, and sustainable for all human beings to develop on this planet[3].

How good the idea of SDGs is, however, in this disruptive era, SME's in Indonesia face more challenges and obstacles that tend to disturb and even inhibit the business growth. It has to realize that in this era many SME's are broke or suddenly dead as the result of competitors that the existence is not realised (invisible competitors). No SME's never faces an obstacle in its growth.

Generally, SME's have not sufficient capacity to overcome those various problems and challenges. Some parties refer to this condition as one of the indicators that the level of competitiveness of SME's in Indonesia is still low at this time. Nevertheless, the premise has not had a strong analytical base so that it takes a study to go deep into the structure of SME's' competitiveness in Indonesia. In this case, the funding problems are the most frequently concerned in the development of SME's' independence, besides human resources, infrastructure, and market. While in the institutional factors, although some researchers do the studies, the aspects appeared are still partial.

Therefore, although this research activity study on the elements mentioned above, the researcher focuses more on the institutional aspects in building the dynamics and independence and the benefits of UMKM.

\section{Method}

Based on the empirical studies conducted, several researchers focused on testing on factors affecting the performance of SME's by involving internal and external factors [4], and characterization of SME's examined the relationship between the characteristics of SMEs[5];[6];[7]. Meanwhile, the factors of resources connectivity and Innovation Actor 
Empowerment have never been touched by previous researchers. Therefore, the researchers reconstruct the model by adding Resources connectivity and Innovation Actor Empowerment as a decisive factor in building a more resilient SME's institution.

The model is constructed as in Figure 3.1 where four independent variables influence the SME's Institution, i.e., external factor $\mathrm{x} 1$, internal factor X2, Resource connectivity $\mathrm{y}$, and innovation actor empowerment y3.

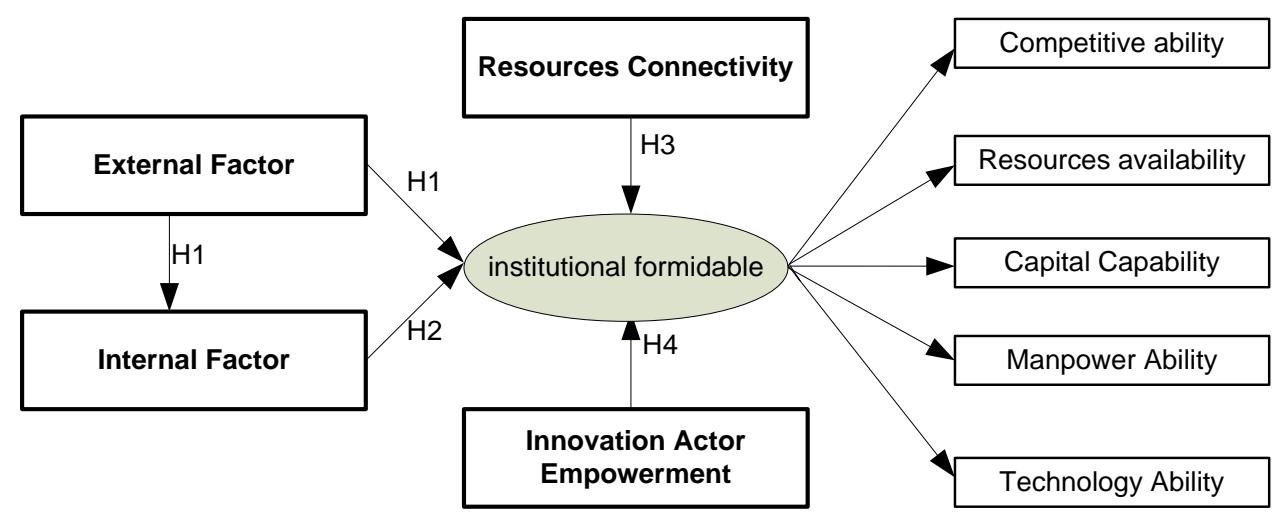

Fig. 1. Conceptual Model Constructed Model Source

The primary data collection was done by approaches; 1) FGD - Forum group discussion, to collect groups of small and medium enterprises based on their business group, such as Stone Craft Industry Group, Horn craft business group, salak pondoh business group, sugarcane craftsmen group and coffee business group. 2) Questionnaires to the respondents were given after the FGD activity, so all the participants who were present could fill in the distributed questionnaire. 3) Deep interviews were conducted when necessary to explore more complete information. The population in this research was all businessmen in 5 KUB (Group of joint business). Sample selection was done by using random sampling method with Slovin formula $[8]$.

\section{Result}

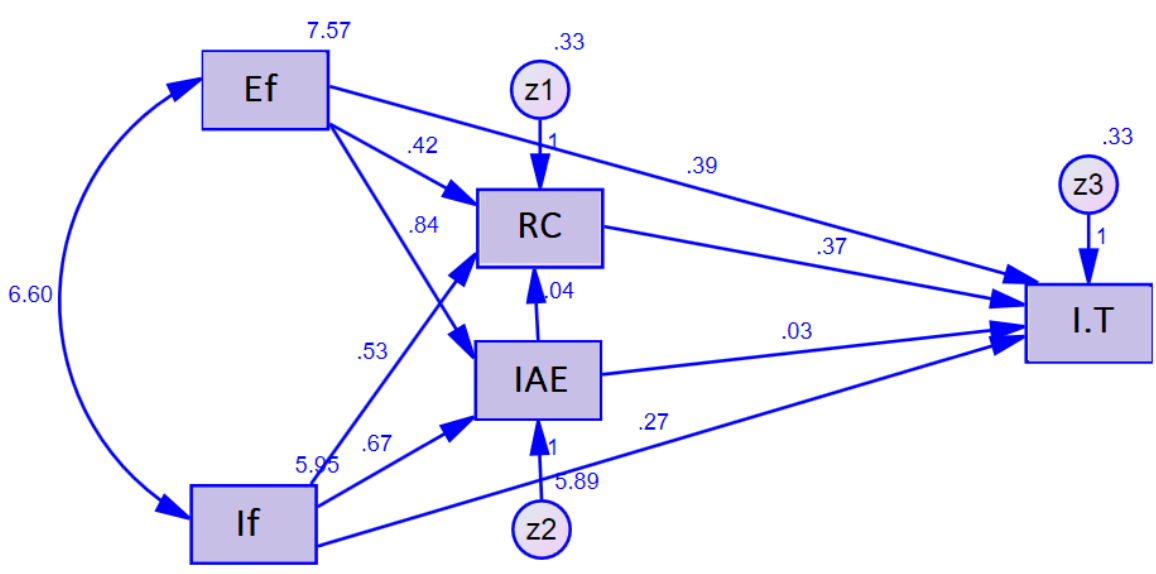


This study used the mix methods design of study by combining qualitative method supported by quantitative methods. This method was chosen to elicit more in-depth answers from the respondents, considering the explorative nature of the research.

With the research approach used, the analysis technique used is Analysis of Movement Structure (AMOS) to test the hypothesis with a quantitative approach. To do this stage, the test of the instrument quality of the research is first carried out by a factor analysis approach. While qualitative testing was done by coding, which aimed to classify the opinions of respondents and find keywords that can be used as a basis of explanation and analysis of the relevance of quantitative results, in this case, AMOS was used to identify the role of moderation of resources connectivity and Innovation Actor Empowerment in influencing the correlation between Internal and External factors in building institutional toughness. The following are the simulation results from the construction of models that have been made through the AMOS program. Two parts can be discussed, namely estimating the value of each parameter and Hypothesis 1. Internal factors have a significant effect on institutional resilience. The contribution of Internal Factors in strengthening institutions shows a strong influence. The results of the analysis show that the estimated value is quite significant $(b=0.273 ; \mathrm{P}<0.05)$. Thus hypothesis 1 can be proven.

Hypothesis 2. External factors have a significant effect on institutional resilience. Judging from the results of the analysis as shown in the table, external factors did not significantly contribute to the strength of SMEs, even though the estimation value was quite significant $(\mathrm{b}=$ $0.375 ; \mathrm{P}>0.05)$ so that hypothesis 2 has not been answered.

Hypothesis 3. Resources Connectivity (Moderator 1) moderates the relationship between External Factors and institutional resilience. The contribution of Resources Connectivity in increasing the strength of the Institute will be significant if accompanied by the role of external factors. The results of the analysis.

\section{a. Model Accuracy Index}

There are so many types of index accuracy models in SEM. The most popular is CMIN, the goodness of fit index (FIGFI), is a comparison comparison index (CCFI) and (RMSEA), about the accuracy of the cutoff index model which can be seen based on the results of the analysis which show the value of kai-squared (CMIN) of 0.583 ( $p>0.05)$. A p-the value of the accuracy of the model. The results are obtained as shown in Table 1.

Table 1. Regression Weight

\begin{tabular}{|c|c|c|c|c|c|c|c|}
\hline & & & Estimate & S.E. & C.R. & $\mathrm{P}$ & Label \\
\hline IAE & $<--$ & If & .668 & .397 & 1.685 & .092 & par_4 \\
\hline IAE & $<--$ & Ef & .836 & .352 & 2.376 & .017 & par_5 \\
\hline $\mathrm{RC}$ & $<---$ & Ef & .415 & .084 & 4.915 & $* * *$ & par_3 \\
\hline $\mathrm{RC}$ & $<---$ & If & .532 & .095 & 5.626 & $* * *$ & par_6 \\
\hline $\mathrm{RC}$ & $<--$ & IAE & .041 & .017 & 2.432 & .015 & par_9 \\
\hline IT & $<--$ & Ef & .391 & .089 & 4.366 & $* * *$ & par_1 \\
\hline IT & $<--$ & If & .273 & .102 & 2.686 & .007 & par_2 \\
\hline IT & $<---$ & $\mathrm{RC}$ & .375 & .071 & 5.288 & .006 & par_7 \\
\hline IT & $<---$ & IAE & .030 & .017 & 1.787 & .074 & par_8 \\
\hline
\end{tabular}

Show that the estimated value $(b=0.273 ; \mathrm{P}<0.05)$. thus the third hypothesis is fulfilled. Hypothesis 4. Innovation Actor Empowerment (Moderator) moderates the relationship between 
Internal Factors and institutional resilience. IAE factor is one of the factors that have the highest contribution in growing the institution's resilience compared to other factors, and IAE has a high gift when it acts as a moderation between internal factors and institutional resilience. The results of the analysis show that the estimated value is quite significant $(b=0.30 ; \mathrm{P} 0.074)$. Although the second hypothesis is not answered, referring to the results of the subsequent analysis shows that Resources connectivity has a substantial contribution to institutional resilience as indicated by the estimated value of 0.344 . This suggests that individually Resouces connectivity contributes to institutional resilience. value above 0.05 if the t-test does not show a significant difference. Well in SEM also, the p-value above 0.05 indicates a difference between the data used to analyse the model being developed. In other words, our model represents our data.

Table 2. Factor analysis test Confirmatory Endogenous Variable Measurement

\begin{tabular}{|l|c|l|}
\hline Goodness of Fit Index & Cut off Value & Result \\
\hline$X^{2}$-Chi Square & Diharapkan Kecil & 219,48 \\
\hline Significance Probability & $\geq 0,05$ & 0,630 \\
\hline RMSEA & $\leq 0,05$ & 1.048 \\
\hline GFI & $\geq 0,90$ & 0.226 \\
\hline AGFI & $\geq 0,90$ & 0,161 \\
\hline CMIN/DF & $\leq 3,00$ & 0,763 \\
\hline TLI & $\geq 0,95$ & 0.0 \\
\hline CFI & $\leq 0,05$ & 1.0 \\
\hline
\end{tabular}

The Goodness of Fit index is a statistical measure whose value has a range between 1.0 (perfect fit) to 0 (poor)[9]. In this case, the GFI value above $90 \%$ is stated as a measure of good fit. The results of the analysis show that the GFI value achieved is 0.226 , which means that the condition is still said to be not good.

\section{b. Evaluation of Measurement Model (Path analysis)}

The evaluation of measurement model was done in three stages: convergence validity test, discriminant validity test and composite reliability test. For Convergent Validity Test, Validity Testing for reflective indicator was done by using the correlation between indicator score and construct score. Measurements with reflective indicators indicated a change in an indicator in a construct if another indicator on the same construct changed. Following was calculation results : 
Table 3. Results of the calculation of the coefficient analysis

\begin{tabular}{|c|c|c|c|c|c|}
\hline \multicolumn{6}{|c|}{ Standard errors for path coefficients } \\
\hline & $\mathrm{RC}$ & IAE & Ext & Inf & IF \\
\hline \multicolumn{6}{|l|}{$\mathrm{RC}$} \\
\hline \multicolumn{6}{|l|}{ IAE } \\
\hline Ext & 0.197 & 0.126 & & & \\
\hline Enf & 0.090 & 0.122 & & & \\
\hline IF & 0.098 & 0.041 & 0.130 & 0.107 & \\
\hline \multicolumn{6}{|c|}{ Effect sizes for path coefficients } \\
\hline & $\mathrm{RC}$ & IAE & Ext & Inf & IF \\
\hline \multicolumn{6}{|l|}{$\mathrm{RC}$} \\
\hline \multicolumn{6}{|l|}{ IAE } \\
\hline Ext & 0.197 & 0.167 & & & \\
\hline Enf & 0.516 & 0.151 & & & \\
\hline IF & 0.130 & 0.004 & 0.278 & 0.541 & \\
\hline
\end{tabular}

The above table shows the standard error and effect size for path coefficients. The standard error values for all variables to the institution sequentially are 0.098 for RC, 0.041 for IAE, 0.130 for External.

Table 4. The Results of the Analysis of The R-Squared Values of Each

\begin{tabular}{|c|c|c|c|c|c|}
\hline & $\mathrm{RC}$ & IAE & Ext & Inf & IF \\
\hline R-squared & & & 0.365 & 0.667 & 0.945 \\
\hline Composite reliab. & 0.835 & 0.852 & 0.820 & 0.883 & 0.866 \\
\hline Cronbach's alpha & 0.689 & 0.731 & 0.704 & 0.823 & 0.806 \\
\hline Avg. var. extrac. & 0.650 & 0.665 & 0.547 & 0.654 & 0.565 \\
\hline Full collin. VIF & 2.748 & 1.655 & 3.968 & 11.748 & 16.677 \\
\hline Q-squared & & & 0.367 & 0.673 & 0.944 \\
\hline
\end{tabular}

The result showed that the value of adjusted R-squared was 0.365 which meant that the external institutional influence of SME's on its institutional toughness moderated by resources connectivity and Innovation Actor Empowerment was 3.65\%. Similarly, the internal institutional factors gave the effect of $66.7 \%$. While the value of AVE for resources connectivity was good enough with an The Path Coefficients and the P-Value test showed that the latent variable of the predictor and the line represented the latent variable criterion. The result of the analysis showed that the variable of Resources Connectivity orientation had an influence on the internal strengthening of the institution of 0.651 and externally of 0.375 as well as for the Innovation Actor Empowerment at a significance level $<0,00$ with the path coefficient value of 0.332 and 0.243 respectively. With the value of $P$ respectively 0,031 and 0,026 .

Meanwhile, the value of effect size for the path was grouped into three categories. They were: weak $(0,02)$, medium $(0,15)$, and big $(0,35)$. The standard error value for the connectivity resources variables was 0.258 and 0.314 for Innovation Actor Empowerment. and 0.107 for Int. As for the generated effect size of all variables to each institute is as big as 0.13 for RC, 0.004 for IAE, in a weak category, and 0.278 for External, and 0.541 for Internal in a solid type. amount $>0.5$ that is 0.65 so that it can be concluded that the convergence validity was high. 
Similarly, the other AVE variables indicate the convergence validity was in moderate criteria. The composite reliability value for all variables was above 0.7 so that they were included in the category of excellent internal consistency reliability. The full collinearity value of VIF was below 0.33 , so it was concluded that there was no collinearity problem in the model. The resulting Q-Squared values for external and internal factor variables were 0.367 and $0.637>0$ which meant that the model had predictive relevanced.

\section{Discussion}

The research that has been done can give an idea about the condition of micro small and medium enterprises (SME's) to some groups of micro small and medium enterprises, especially those that spread in Magelang regency. The number of small and medium industries in Magelang Regency reaches 39,580 SME's in 2016 [1]. Although it is quite large in quantity, the condition of SME's in Magelang District is still far from the expectations. From year to year, it tends to fluctuate the number. It indicates that SME's in Indonesia, especially in Magelang have not been tough yet. Various approaches have done by many researchers to analyse multiple problems faced.

Such aid will affect the performance of the institution so that the role of SOE, as one of the agents of development assigned by the government, has a strategic position. Not to mention PT Bank BRI, this sees from the aspect of entrepreneurship orientation owned by SME's. External factors encountered can include environmental dynamics, price competition and access to capital, and the performance of SME's.

Seen from the institutional aspect, it can be disclosed that the variation of MSME institution that gets mentoring assistance is quite diverse. It provides a positive element for the development of cross-sector SME's business. However, the focus of the aid offered to regionalbased business groups to empower regional economic potential has not been sharply prioritised. The FGD results mention the need for mentoring and advocacy that are routinely given an evaluation of their performance. Such mentoring includes management, marketing, entrepreneurship, development and innovation and technology adoption. In other words, small business groups require actors to strengthen their businesses and institutions. These actors may be from their group members, but may also come from agencies specifically assigned to assist and empower specific industry businesses group.

Similarly, when FGDs are conducted amongst small business groups, besides difficulties in building business networks in optimising the connectivity between entrepreneurs, raw material problems become problems that require immediate solutions. The limitation of raw materials is a severe constraint to output growth or production sustainability for SME's in Indonesia. Many entrepreneurs are forced to quit the business and move the profession to other economic activities due to the problem of raw material limitations.

This study internalises the resource connectivity and innovation actor empowerment aspects in internal and external variables of the business group in building a strong institution. Both elements serve as a moderating factor in the construction of institutional strengthening models. The structural model (inner model) can be analysed by taking a closer look at R-Square for the dependent construct. The result shows the value of adjusted R-Square reach 0.365 for external factor and 0,667 for the internal element. The amount of AVE for Resources Connectivity is quite good with a value $>0.5$ that is 0.65 , and for Innovation Actor Empowerment is almost the same that is 0.665 . This shows that the convergence validity is high. For composite values, the overall reliability is above 0.8 . This means the reliability of internal consistency is outstanding. 


\section{Conclusion}

Many institutional strengthening towards competing SME's is done, among others, with the strategy to increase the internal potential that includes the aspects of human resources skills, finance and financing aspects, production process aspects, and market aspects, as well as external potential strategies covering aspects of government support, socio-economic issues, as well as aspects of institutional support. Both approaches have contributed significantly to the improvement of SME's' capabilities. To further strengthen the institution to be more resilient, the research includes two new variables of resource connectivity covering aspects of cooperation on the procurement of source of raw materials, more comprehensive market link, and capital utilisation. The next variable is the Innovation Actor Empowerment which includes aspects of technical assistance, availability of mentor/trainer, and issues of technological innovation and transformation.

The result of factor analysis with structural equation modelling partial least square method shows that internal and external factors influence and contribute to the institutional toughness of SMEs of 0.365 which means that the foreign influence of MSME institution to its institutional resilience moderated by resources connectivity and Innovation Actor Empowerment is equal to $36.5 \%$. Similarly, the internal factors of the institute effect $66.7 \%$.

Model test results show that external and internal factors are strongly correlated in institutional strengthening. Similarly, resources connectivity and Innovation Actor Empowerment contribute to the toughness of SME's institutions through several programs that include, provision and procurement of collectively integrated raw materials, networking with broader markets, especially for larger industrial enterprises with broader market reach and capital utilisation from the outside. The programs of innovation actor empowerment include technical assistance programs either local, OPD and from other institutions regularly mentored by Actor Empowerment include assistance, advocacy, and motivation and innovation, transformation and technology adoption.

\section{References}

[1] Rizky Natassia, "Pengaruh Gaya Kepemimpinan Dan Motivasi Kerja Terhadap Kinerja Karyawan Badan Pusat Statistik (BPS) Kota Padang," economica, vol. 2, no. 2, hlm. 134 143, Jul 2015.

[2] S. Sumekar dan U. Haryadi, Sosialisasi Sustainable Deveopment Goals (SDGs) Implementasi di Perpustakaan. 2016.

[3] D. Osborn, U. Cutter, dan F., Universal Sustainable Development Goals Understanding the Transformational Challenge for Developmed Countries. Stakeholder Forum. 2015.

[4] R. Purwaningsih dan Kusuma, Analisis Faktor-faktor yang Mempengaruhi Kinerja Usaha Kecil Menengah Dengan Metode Structural Equation Modeling (Studi kasus UKM Berbasis Industri Kreatif Kota Semarang), Prosiding SNST ke-5. 2015.

[5] N. Indiarti dan M. Langenberg, Factors Affecting Business Success Among SME's: Empirical Evidences from Indonesia. 2004.

[6] D. Storey, Understanding the small business sector. London: Routledge, 1994.

[7] H. Hansen, R. John., dan T. Finn, "SME Growth and Survival in Vietnam: Did Direct Government Support Matter?, Discussion Papers," University of Copenhagen. Department of Economics, 04-13, 2004.

[8] Sugiyono, Metode Penelitian Pendidikan, . Bandung,: penerbit Alfabeta, 2010.

[9] I. Ghazali, Structural Equations Model Concepts \& Applications with the AMOS 19.0 Program. Semarang: Undip, 2011. 
